\title{
Preparation and Characterization of Activated Carbon Obtained from Plantain (Musa paradisiaca) Fruit Stem
}

\author{
O. A. Ekpete, A. C. Marcus, and V. Osi \\ Department of Chemistry, Ignatius Ajuru University of Education, PMB 5047, Rumuolumeni, Rivers State, Nigeria \\ Correspondence should be addressed to V. Osi; osivalentine02@gmail.com
}

Received 19 December 2016; Accepted 6 March 2017; Published 23 March 2017

Academic Editor: Henryk Kozlowski

Copyright (C) 2017 O. A. Ekpete et al. This is an open access article distributed under the Creative Commons Attribution License, which permits unrestricted use, distribution, and reproduction in any medium, provided the original work is properly cited.

Carbonization of carbon obtained from plantain (Musa paradisiaca) stem was achieved at a temperature of $400^{\circ} \mathrm{C}$ for one hour. The carbonized carbon was divided into two parts to be activated separately. The activated carbon CPPAC (carbonized plantain phosphoric acid activated carbon) and CPZAC (carbonized plantain zinc chloride activated carbon) were produced via the chemical activation process using $\mathrm{H}_{3} \mathrm{PO}_{4}$ and $\mathrm{ZnCl}_{2}$. Characterization of $\mathrm{pH}$, bulk density, moisture content, ash content, volatile matter, iodine number, and oxygen functional group was conducted. When comparing the surface properties of both CPPAC and CPZAC with the untreated plantain carbon (UPC), it was observed that there existed significant differences in all properties with the exemption of carboxylic group for CPPAC and phenolic group for both CPPAC and CPZAC, thus signifying that a chemical transformation did occur. When comparing the results obtained from CPPAC to that of CPZAC, CPPAC was more preferable for adsorption due to its low bulk density, low ash content, and high iodine value, signifying thus that the activating agents both reacted differently with the plantain stem.

\section{Introduction}

The importance of activated carbon cannot be overemphasized, thus leading to the search of means for its production other than the known traditional methods, due to its applicability in all or almost all of life's endeavours. Based on this, researches and projects are embarked upon, on the use of different agricultural byproducts to produce activated carbon [1-6]. As the world continues to develop with almost every habitat of man gearing towards urbanization, there is every tendency that the need for activated carbon would also increase, hence, the need for individuals, companies, and countries to be prepared to meet this demand. The production of activated carbon from agricultural byproducts has both economic and environmental effects, as it converts unwanted, low-value agricultural waste to useful high-value adsorbent [7].

Plantain (Musa paradisiaca) is a plant of banana family (Musaceae) closely related to common banana (Musa sapientum). Its fruits are edible and are generally used for cooking. This is different from the soft and sweet banana.
Plantain as of 2004 was grown in a total of 52 countries, which were said to be world's producers of plantain, producing a total of 33 million metric tons [8]. Despite the downward trend of plantain production in Nigeria between 1990 and 2004, it was still ranked fifth in the world $[9,10]$ with eight African countries named among the top ten plantain producers in the world [11]. Today, plantain is grown in at least 107 countries with world's production of over 76 million metric tons with a downward trend in terms of plantain yields per hectare in Nigeria. Currently Nigeria ranks sixth and is the world's largest producer in West Africa with an annual production of about 2.4 million metric tons mostly obtained from the southern states $[9,12]$. Despite its prominence, Nigeria does not feature among plantain exporting nations; it produces more for local consumption than export [12].

The production of activated carbon from agricultural byproducts has potential economic and environmental impacts. Firstly, it converts unwanted low-value agricultural waste to high-value adsorbents. Secondly, activated carbons are increasingly used in water to remove organic chemicals and metals of environment and economic concern. Finally, 
it will reduce the importation of activated carbon wherefore increasing our economic base as a country [2]. Thus the purpose of this purpose of this study is to prepare and characterize the carbons obtained from plantain fruit stem, activated with orthophosphoric acid zinc chloride and the untreated carbon.

\section{Materials and Method}

2.1. Sample Collection and Preparation. Plantain fruit stems were collected from a market in Port Harcourt Local Government Area of Rivers State. The stems were cut into smaller bits and sundried for 3-4 days and then oven-dried at a temperature of $120^{\circ} \mathrm{C}$ for 8 hours and pulverized to fine powder.

2.2. Carbonization and Chemical Activation. Carbonization was done using the box-type resistance furnace at a temperature of $400^{\circ} \mathrm{C}$ for $1 \mathrm{hr}$. The charcoal product was allowed to cool down and then divided into two parts, $\mathrm{A}$ and $\mathrm{B}$, using $\mathrm{H}_{3} \mathrm{PO}_{4}$ and $\mathrm{ZnCl}_{2}$ as activating agents $[2,3,7,13,14]$. The activated carbons were produced with a slight modification using standard methods of Ekpete [2] and Sugumaran [3]. Two beakers were used in the activation process. In the first beaker, $70 \mathrm{~g}$ of the charcoal product was mixed with $100 \mathrm{~cm}^{3}$ $10 \% \mathrm{w} / v$ of $\mathrm{ZnCl}_{2}$ and another $70 \mathrm{~g}$ was mixed with $500 \mathrm{~cm}^{3}$ 0.3 moldm $^{-3} \mathrm{H}_{3} \mathrm{PO}_{4}$ in the second beaker.

The beaker contents $\left(70 \mathrm{~g}\right.$ of the charcoal $+100 \mathrm{~cm}^{3}$ $10 \% w / v$ of $\mathrm{ZnCl}_{2}$ and $70 \mathrm{~g}$ of the charcoal $+500 \mathrm{~cm}^{3}$ 0.3 moldm $^{-3} \mathrm{H}_{3} \mathrm{PO}_{4}$ ) were thoroughly mixed using a heating mantle at a constant temperature of $80^{\circ} \mathrm{C}$ until it formed a paste. The paste was then transferred into a crucible. The crucible was placed in the furnace where it was heated at a temperature of $400^{\circ} \mathrm{C}$ for $1 \mathrm{hr}$. It was allowed to cool and washed with distilled water until a neutral $\mathrm{pH}$ was obtained, oven-dried at $100^{\circ} \mathrm{C}$ for $12 \mathrm{hrs}$, and then kept in air tight pack for further analysis and labelled as CPZAC (carbonized plantain zinc chloride activated carbon), CPPAC (carbonized plantain phosphoric acid activated carbon), and UPC (untreated plantain carbon).

2.3. Determination of $\mathrm{pH}$. The $\mathrm{pH}$ was determined by using the method of Abdullah [15] with a slight modification. $1.0 \mathrm{~g}$ carbon sample of each of CPPAC, CPZAC, and UPC was put into a beaker containing $100 \mathrm{~mL}$ of water and then boiled for 5 minutes. The $\mathrm{pH}$ was measured after the solution was diluted to $200 \mathrm{~mL}$ and cooled to room temperature.

2.4. Determination of Bulk Density. Determination of bulk density was used done using the methods of Sugumaran [3] with a slight modification. A glass cylinder $(25 \mathrm{~mL})$ was filled to a specified volume with 40-mesh powder carbon sample of each of CPPAC, CPZAC, and UPC and dried in an oven at $105^{\circ} \mathrm{C}$ overnight. The cylinder was tapped for 1-2 minutes to compact the carbon and the bulk density calculated and presented as $\mathrm{g} / \mathrm{mL}$ following the formula:

$$
\text { Bulk density }=\frac{\text { Mass of sample }(\text { dry })}{\text { Volume of measuring cylinder }} \times 100 \text {. }
$$

2.5. Moisture Content Determination. Thermal drying method was used in the determination of moisture content of the samples. $1.0 \mathrm{~g}$ of the start carbons (carbonized and uncarbonized) was weighed in triplicate and placed in clean, dried, and weighed crucible. The crucibles were placed in an oven at $105^{\circ} \mathrm{C}$ to constant weight for $4 \mathrm{hr}$ according to the method of Rengaraj [16]. The difference between the initial and final mass of the carbon represents the moisture content. The percentage moisture content (\%) was computed as follows:

$$
\text { Moisture } \%=\frac{\text { loss in weight on drying }(\mathrm{g})}{\text { Initial weight }(\mathrm{g})} \times 100 \text {. }
$$

2.6. Ash Content and Volatile Matter Determination. For ash content determination, crucibles were preheated to about $500^{\circ} \mathrm{C}$, then cooled in a desiccator, and weighed. $1.0 \mathrm{~g}$ of each sample was transferred into the crucibles and reweighed. The crucibles containing the samples were then placed in the furnace and the temperature was allowed to rise to $500^{\circ} \mathrm{C}$ for about $1 \mathrm{hr} 30 \mathrm{~min}$ and allowed to cool in a desiccator to room temperature $\left(30^{\circ} \mathrm{C}\right)$ and reweighed. The ash content was calculated using the equation

$$
\text { Ash } \%=\frac{\text { Ash weight }}{\text { Oven dry weight }} \times 100 \text {. }
$$

For volatile matter determination, $1.0 \mathrm{~g}$ of each sample was heated at a temperature of $500^{\circ} \mathrm{C}$ for 10 minutes. The volatile matter was calculated using the equation

$$
\begin{aligned}
\text { Volatile }(\%)= & \frac{\text { Weight of volatile component }(\mathrm{g})}{\text { Oven dry weight }(\mathrm{g})} \\
& \times 100,
\end{aligned}
$$

where volatile weight is the difference in weight before and after heating of the samples.

2.7. Determination of Iodine Number. For iodine number test, each sample of carbon $(0.3 \mathrm{~g}, 0.5 \mathrm{~g}$, and $0.7 \mathrm{~g}$ ) was put into $250 \mathrm{~cm}^{3}$ conical flask and $10 \mathrm{~cm}^{3}$ of $5 \% \mathrm{HCl}$ was added and stirred. Then $100 \mathrm{~mL}$ of stock iodine solution ( $2.7 \mathrm{~g}$ of iodine and $4.1 \mathrm{~g}$ of KI in IL of deionized water) which was standardized using a standard solution of sodium thiosulphate $(0.1 \mathrm{M})$ was added to it and the mixture was shaken for a period of 20 mins. The mixture was filtered using a filter paper. An aliquot portion $(30 \mathrm{~mL})$ was titrated with $0.1 \mathrm{M}$ sodium thiosulphate using starch as indicator. 
TABLE 1: Physical characteristics of carbon samples.

\begin{tabular}{lccr}
\hline Property & CPZAC & CPPAC & UPC \\
\hline $\mathrm{pH}$ & $9.30 \pm 0.06$ & $8.50 \pm 1.70$ & $6.80 \pm 0.06$ \\
Bulk (g/mL) & $0.34 \pm 0.00$ & $0.32 \pm 0.05$ & $0.38 \pm 0.01$ \\
Moisture (\%) & $7.33 \pm 1.15$ & $10.33 \pm 2.08$ & $15.30 \pm 1.15$ \\
Ash (\%) & $31.00 \pm 6.08$ & $20.00 \pm 1.53$ & $25.50 \pm 3.29$ \\
Volatile (\%) & $32.33 \pm 1.15$ & $23.33 \pm 1.53$ & $72.33 \pm 2.51$ \\
\hline
\end{tabular}

Results are given as mean \pm standard deviation (triplicate values).

$\mathrm{CPZAC}=$ carbonized plantain zinc chloride activated carbon, $\mathrm{CPPAC}=$ carbonized plantain phosphoric acid activated carbon, and UPC $=$ untreated plantain carbon.

The percent iodine adsorbed by each carbon was calculated by applying the formula below.

$$
\frac{\left(\mathrm{mL} \text { of } \mathrm{Na}_{2} \mathrm{~S}_{2} \mathrm{O}_{3} \text { in blank }-\mathrm{mL} \mathrm{Na}_{2} \mathrm{~S}_{2} \mathrm{O}_{3}\right. \text { in sample) }}{\mathrm{mL} \text { of } \mathrm{Na}_{2} \mathrm{~S}_{2} \mathrm{O}_{3} \text { in blank }}
$$

$$
\times 100
$$

2.8. Determination of Oxygen Containing Functional Groups. The Boehm titration method as used by Ekpete and Horsfall [7] was used for this analysis with a slight modification. $2.0 \mathrm{~g}$ of each carbon samples was kept in contact with $50 \mathrm{~mL}$ solution of $\mathrm{NaHCO}_{3}(0.1 \mathrm{M}), \mathrm{Na}_{2} \mathrm{CO}_{3}(0.05 \mathrm{M})$, and $\mathrm{NaOH}$ $(0.1 \mathrm{M})$ for acidic group and $0.1 \mathrm{M} \mathrm{HCl}$ for basic groups for more than two days. Subsequently the aqueous solutions were back-titrated with $\mathrm{HCl}(0.1 \mathrm{M})$ for acidic and $\mathrm{NaOH}$ $(0.1 \mathrm{M})$ for basic group. The number and type of acidic sites were calculated by considering that $\mathrm{NaOH}$ neutralizes carboxylic, lactonic, and phonetic groups. $\mathrm{Na}_{2} \mathrm{CO}_{3}$ neutralizes carboxylic and lactonic group and the $\mathrm{NaHCO}_{3}$ neutralizes only carboxylic groups.

Carboxylic groups were therefore quantified by direct titration with $\mathrm{NaHCO}_{3}$-; the difference between the groups titrated with $\mathrm{Na}_{2} \mathrm{CO}_{3}$ and those titrated with $\mathrm{NaHCO}_{3}$ was assumed to be lactones and the difference between the groups titrated with $\mathrm{NaOH}$ and those titrated with $\mathrm{Na}_{2} \mathrm{CO}_{3}$ was assumed to be phenols. Basic site was determined by titration with $\mathrm{HCl}$. Neutralization points were known using $\mathrm{pH}$ indicators of phenolphthalein solution for titration of strong base and strong acid, while methyl red solution was used for the titration of weak base and strong acid.

2.9. FTIR Analysis. The Fourier transform Infrared (FTIR) analysis of the samples was carried out by FTIR equipment of mark SPECTRUM ONE FTIR incorporated with software (Perkin Elmer Instruments version 3.02.01) for the examination of the spectra. For sample analysis, $0.5 \mathrm{~g}$ of activated carbon was mixed with about the same amount of potassium bromide $\mathrm{KBr}$. The mixture thus obtained was crushed in a mortar to obtain a homogeneous powder which was then introduced into a mould to obtain very fine plates. The plates were then introduced into the spectrophotometer for analysis. The wave number was found to vary between 4000 and $350 \mathrm{~cm}^{-1}$.

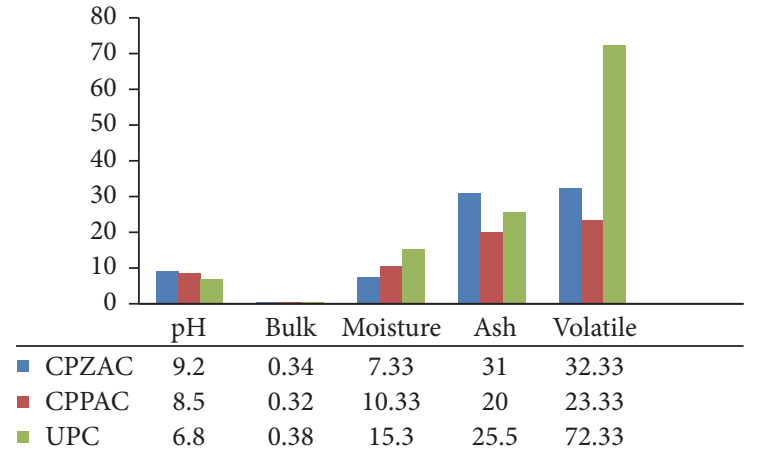

Figure 1: Physical characteristics of carbon sample.

\section{Results and Discussion}

3.1. Activation and Carbonization. The temperature for carbonization is a factor that is usually taken into consideration because of how dependent all other properties of the carbon are on it. Precautionary measures are usually taken when choosing a temperature due to the fact that above certain temperatures the sample will completely change to ash. Temperatures within the range of $200-1100^{\circ} \mathrm{C}$ have been in constant use for preparation of activated carbon which is also dependent on the method of activation. The temperature choice of $400^{\circ} \mathrm{C}$ was used taking into consideration two factors which were based on the method of activation and an observation made by Sugumaran [3] while working with banana stem. Despite its environmental unfriendliness, chemical activation method has been thriving over physical activation method due to its low energy cost, high carbon yield, and easy recovery process of activating agents which have been reported to act as dehydrating agents, tar formation inhibitor, carbon yield enhancer, and bond cleavage promoter $[3,17]$.

3.2. Surface Characteristics of Carbon Samples. Low amount of moisture, ash, and volatile matter indicates that the particle density is relatively small and that the biomaterial should be an excellent raw material for adsorbents to be used in column or fixed-bed reactors [7]. This assertion can be said to be true when taking CPPAC into consideration. As presented in Figure 1 and Table 1, it can be observed that they all had low amount of moisture, with the CPZAC having the lowest moisture content value of $7.33 \pm 1.15$; the moisture value of 
TABLE 2: Iodine adsorption of samples in relation to their doses.

\begin{tabular}{lccc}
\hline DOSE & CPZAC & CPPAC & UPC \\
\hline $0.3 \mathrm{~g}$ & $57.00 \pm 0.00$ & $64.00 \pm 1.41$ & $24.50 \pm 6.36$ \\
$0.5 \mathrm{~g}$ & $72.50 \pm 2.12$ & $81.50 \pm 2.12$ & $51.00 \pm 0.00$ \\
$0.7 \mathrm{~g}$ & $84.50 \pm 2.12$ & $92.50 \pm 2.12$ & $64.00 \pm 2.12$ \\
\hline
\end{tabular}

Results are given as mean \pm standard deviation (triplicate values). $\mathrm{CPZAC}=$ carbonized plantain zinc chloride activated carbon, $\mathrm{CPPAC}=$ carbonized plantain phosphoric acid activated carbon, and UPC $=$ untreated plantain carbon.

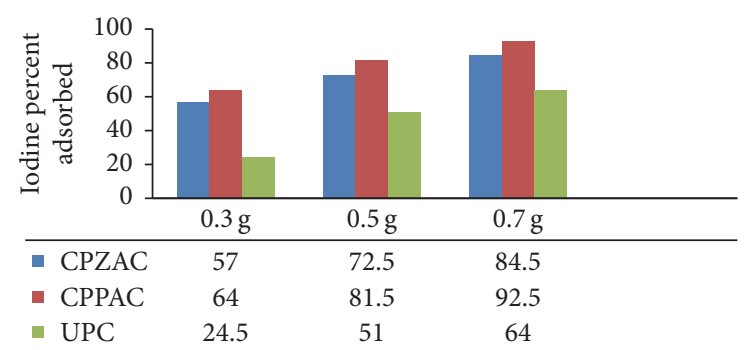

FIGURE 2: Iodine adsorption chart.

all samples was also lower than the $19.50 \pm 0.02$ observed by Ekpete and Horsfall [7]. The ash value and volatile matter values made CPPAC more preferable for adsorption; ash content influences ignition point of the carbon, which is a major consideration where adsorption of certain solvents is applied; it reduces the overall activity of activated carbon and the efficiency of reactivation; the lower the ash value, the better the activated carbon for use as adsorbent. Abdullah et al. [15] while trying to work on this factor opined that ash values that make a carbon suitable for absorption should be within a range of $1-20 \%$, thus making CPPAC a better choice followed by UPC and CPZAC if the ash value is to be considered. But this was not the case as CPZAC proved to be a better adsorbent than UPC. The volatile content was greater in UPC having a value of $72.33 \pm 2.51$ followed by CPZAC and CPPAC making the adsorbent properties for these samples to be attributed to their volatile matter content. This difference can be attributed to carbonization and activation processes which have to a large extent dried and volatilized all noncarbon materials [7].

Iodine number is usually used to roughly estimate the surface area of activated carbon at room temperature condition. It is used as an indicator for the porosity and adsorbent capacity of the activated carbon. The higher iodine number of carbons has been attributed to the presence of large micropore structure and to the great probability of carbons to have a large surface area due to enlargement of their pore structure $[7,14]$. The results of iodine removed by different carbon samples at doses $0.3,0.5$, and 0.7 grams are presented in Figure 2 and Table 2.

As observed in Table 2 and Figure 2, the iodine value of all samples increased with increased concentration of samples with CPPAC having the highest iodine value in all the concentrations used. The huge difference that existed between UPC and CPZAC/CPPAC has been attributed to
TABLE 3: The effect of different activation methods on surface (oxygen containing) functional groups of carbon samples.

\begin{tabular}{lccc}
\hline GROUPS & CPZAC & CPPAC & UPC \\
\hline Carboxylic (meq/g) & 0.08 & 0.09 & 0.09 \\
Lactones (meq/g) & 0.10 & 0.08 & 0.13 \\
Phenols (meq/g) & 0.02 & 0.03 & 0.05 \\
Total basic sites (meq/g) & 2.51 & 1.62 & 0.68 \\
\hline
\end{tabular}

Results are based on one-time analysis.

$\mathrm{CPZAC}=$ carbonized plantain zinc chloride activated carbon, $\mathrm{CPPAC}=$ carbonized plantain phosphoric acid activated carbon, and UPC $=$ untreated plantain carbon.

the presence of large micropore structure which may due to chemisorption taking place in the pores of the carbons during carbonization and activation, while that of CPZAC and CPPAC is attributed to the different reactivity rate with the activating agents $[3,14]$.

Although been used by many researchers, Boehm titration has not been standardized for use with Biochars. It is not clear whether measurements of Biochars made using Boehm titration are accurate; this has led to difficulties in comparison of results of Boehm titration from different studies [18]. Boehm's method gives a semiquantitative measure of surface functionalities because the chemical groups are more complex than shown in Boehm titrations.

With $\mathrm{NaHCO}_{3}, \mathrm{Na}_{2} \mathrm{CO}_{3}, \mathrm{NaOH}$, and $\mathrm{HCl}$ thought to be neutralizing carboxylic groups, lactonic and carboxylic groups, lactonic, carboxylic, and phenolic groups, and all basic groups, the nominal observation of the values showed that there was no much difference existing between the carbon samples when the acidic sites are taken into consideration. As presented in Table 3, it was observed that there existed tremendous variations in basic sites of the sample as CPZAC had the highest number of basic sites followed by CPPAC with UPC having the least number of basic sites as these values corresponded to the $\mathrm{pH}$ values.

3.3. FTIR Analysis. From the FTIR analysis of the samples as presented in Figures 3(a), 3(b), and 3(c), it can be noticed that they all shared common peaks and value which is to justify the fact that they are the same sources. Some of the peaks are thus explained below. Figure 3(b) (CPPAC) and Figure 3(c) (CPZAC) had strong broad bands at $3437.53 \mathrm{~cm}^{-1}$ and $3436.66 \mathrm{~cm}^{-1}$ while Figure 3(a) (UPC) had a very broad band ranging from 3500 to $3000 \mathrm{~cm}^{-1}$; those of CPPAC and CPZAC corresponded to an $-\mathrm{OH}$ group from an alcohol while that of UPC corresponded to an -OH group vibration probably from a hydroxyl group; 2920,2850 , and $1380 \mathrm{~cm}^{-1}$ which were present in all samples corresponded to a C-H stretch. Bands between 1630 and $1640 \mathrm{~cm}^{-1}$ were observed to be strong in CPPAC and CPZAC and very strong in UPC; the strong bands corresponded to $\mathrm{C}=\mathrm{C}$ alkene stretch while the very strong bands corresponded to a $\mathrm{C}=\mathrm{O}$ stretch probably from an amide.

Bands between 1100 and $1110 \mathrm{~cm}^{-1}$ were found to be present in both CPPAC and UPC while a band at $1035 \mathrm{~cm}^{-1}$ 


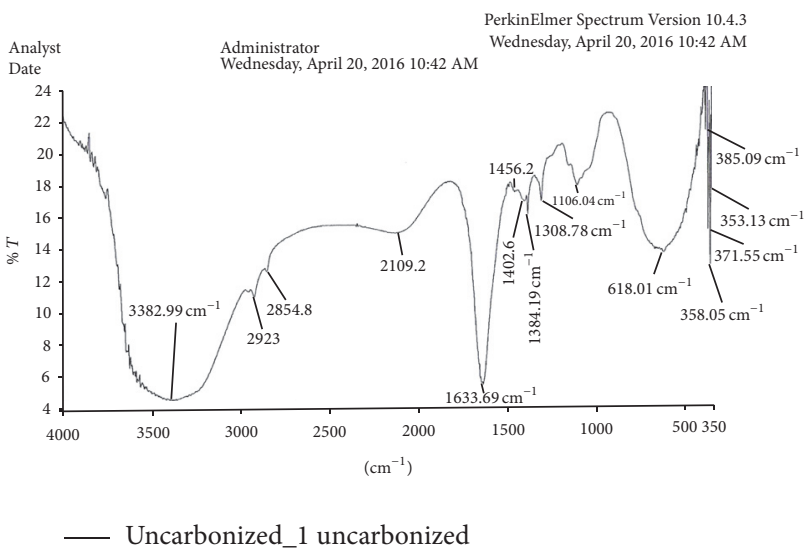

(a)

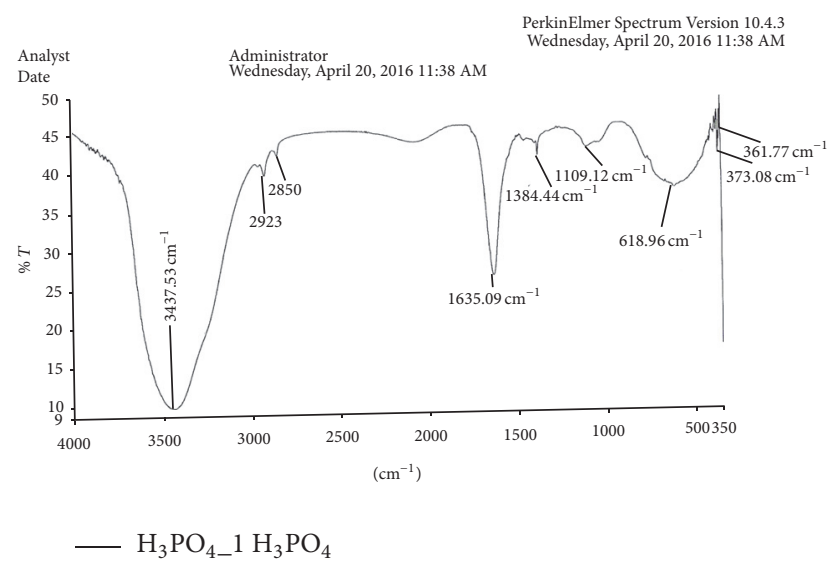

(b)

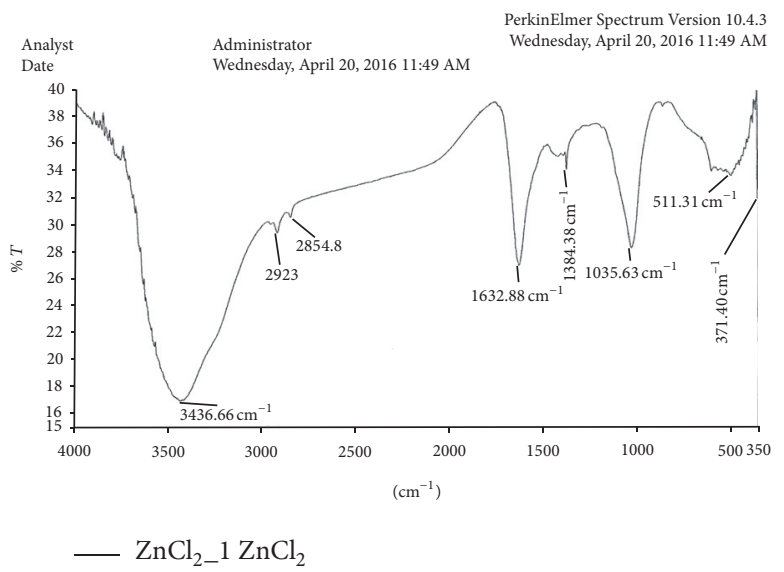

(c)

FIGURE 3: (a) FTIR analysis of UPC. (b) FTIR analysis of CPPAC. (c) FTIR analysis of CPZAC. UPC = untreated plantain carbon, CPPAC = carbonized plantain phosphoric acid activated carbon, and CPZAC = carbonized plantain zinc chloride activated carbon.

was found to be present in CPZAC alone. The absence of bands at $1456 \mathrm{~cm}^{-1}$ and $1402 \mathrm{~cm}^{-1}$ in CPPAC and CPZAC which was present in UPC indicates that a chemical transformation did occur. The shift, absence, or presence of bands in CPPAC and CPZAC also signifies that the samples reacted differently with the various activating agents.

\section{Conclusion}

This study showed that indeed activated carbon of desirable qualities can be obtained from plantain stem. It was also observed that some theoretical assumptions that had been postulated as to the relationship were found to be true, for example, the relationship between $\mathrm{pH}$ and Boehm titrations, bulk density and liquid phase adsorption, and the IR spectra and moisture content.

\section{Conflicts of Interest}

The authors have no conflicts of interest.

\section{Acknowledgments}

The authors would like to express their gratitude to friends who made this work a reality especially Moses Onyejiekwe, Patience Nuate, Edori Simeon, and Chioma Festus.

\section{References}

[1] O. A. Ekpete, F. Kpee, J. C. Amadi, and R. B. Rotimi, “Adsorption of chromium(VI) and zinc(II) ions on the skin of orange peels (Citrus sinensis)," Journal of Nepal Chemical Society, vol. 26, pp. 31-39, 2010.

[2] O. A. Ekpete, M. Horsfall Jr., and T. Tarawou, "Adsorption of chlorophenol from aqueous solution on fluted and commercial activated carbon," Journal of Nepal Chemical Society, vol. 27, pp. 1-10, 2011.

[3] P. Sugumaran, S. V. Priya, P. Rauichandran, and S. Seshadri, "Production and characterization of activated carbon from banana empty fruit bunch and delonix regia fruit pod," Journal of Sustainable Energy and Environment, vol. 3, no. 1, pp. 125-132, 2012. 
[4] S. E. Abechi, C. E. Gimba, A. Uzairu, and V. A. Dallatu, "Preparation and characterization of activated carbon from palm kernel shell by chemical activation," Research Journal of Chemical Science, vol. 3, no. 7, pp. 54-61, 2013.

[5] R. I. Santi and M. Zakir, "The adsorption of $\mathrm{Pb}(\mathrm{II})$ ions on activated carbon from rice husk, irradiated by ultrasonic waves: kinetic and thermodynamics studies," Journal of Natural Sciences Research, vol. 4, no. 2, pp. 18-24, 2014.

[6] G. O. El-Sayed, M. M. Yehia, and A. A. Asaad, "Assessment of activated carbon prepared from corncob by chemical activation with phosphoric acid," Water Resources and Industry, vol. 7-8, pp. 66-75, 2014.

[7] O. A. Ekpete and M. Horsfall Jr., "Preparation and characterization of activated carbon derived from fluted pumpkin stem waste (Telfairia occidentalis hook f)," Research Journal of Chemical Sciences, vol. 1, no. 3, pp. 10-17, 2011.

[8] Food and Agriculture Organization, AGROSTAT Database (2004): Food and Agriculture Organisation of United Nations, Production Year Book, FAO, Rome, Italy, 2004.

[9] Food and Agriculture Organisation, AO Stat (2006): FAO Statistics Division 2006. Food and Agriculture Organisation of the United Nations. Production Year Book, FAO, Rome, Italy, 2006.

[10] Food and Agriculture Organisation, FAO Stat (2011): Plantain Production quality in Nigeria. Food and Agriculture Organisation of the United Nations. Production Year Book, FAO, Rome, Italy, 2011.

[11] P. E. Kainga and I. T. Seiyabo, "Economics of plantain production in Yenagoa Local Government Area of Bayelsa State," Journal of Agriculture and Social Research, vol. 12, no. 1, pp. 114123, 2012.

[12] C. C. Olumba,, "Productivity of improved plantain technologies in Anambra State, Nigeria," African Journal of Agricultural Research, vol. 9, no. 29, pp. 2196-2204, 2014.

[13] R. Malik, D. S. Ramteke, and S. R. Wate, "Physico-chemical and surface characterization of adsorbent prepared from groundnut shell by $\mathrm{ZnCl}_{2}$ activation and its ability to adsorb colour," Indian Journal of Chemical Technology, vol. 13, no. 4, pp. 319-328, 2006.

[14] J. Sahira, A. Mandira, B. P. Prasad, and R. P. Ram, "Effect of activating agents on the activated carbons prepared from lapsi seed stone," Research Journal of Chemical Science, vol. 3, no. 5, pp. 19-24, 2013.

[15] A. H. Abdullah, A. Kassim, T. Zainal et al., "Preparation and characterization of activated carbon from gelam wood bark (Melaleuca cajuputi)," Malaysian Journal of Analytical Sciences, vol. 7, no. 1, pp. 65-68, 2000.

[16] S. Rengaraj, S.-H. Moon, R. Sivabalan, B. Arabindoo, and V. Murugesan, "Agricultural solid waste for the removal of organics: adsorption of phenol from water and wastewater by palm seed coat activated carbon," Waste Management, vol. 22, no. 5, pp. 543-548, 2002.

[17] H. V. Montoya, S. J. Garcia, and J. I. Bueno-Lopez, “Thermal treatments and activation procedures used in the preparation of activated carbons," in Lignocellulosic Precursors Used in the Synthesis of Activated Carbon-Characterization Techniques and Applications in the Wastewater Treatment, H. V. Montoya, Ed., pp. 2-21, InTech, Mexico City, México, 2012.

[18] B. F. Rivka, Evaluation and implementation of methods for quantifying organic and inorganic components of biochar alkalinity [M.S. thesis], Lowa State University, Ames, Iowa, USA, 2012. 

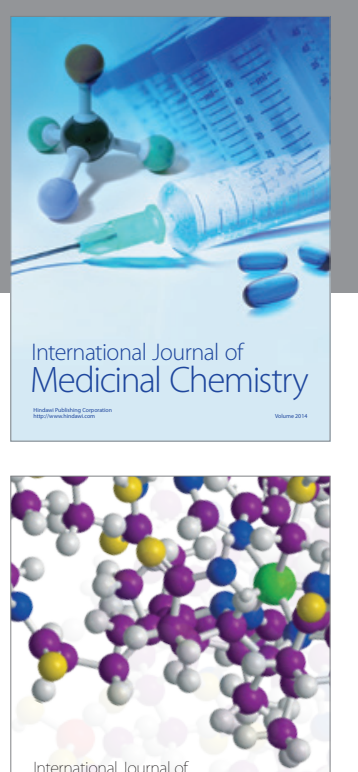

Carbohydrate Chemistry

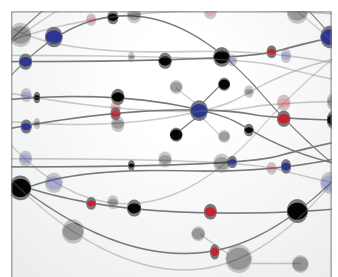

The Scientific World Journal
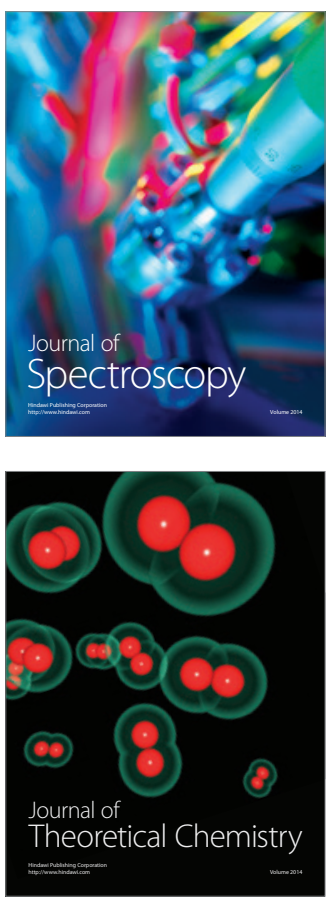
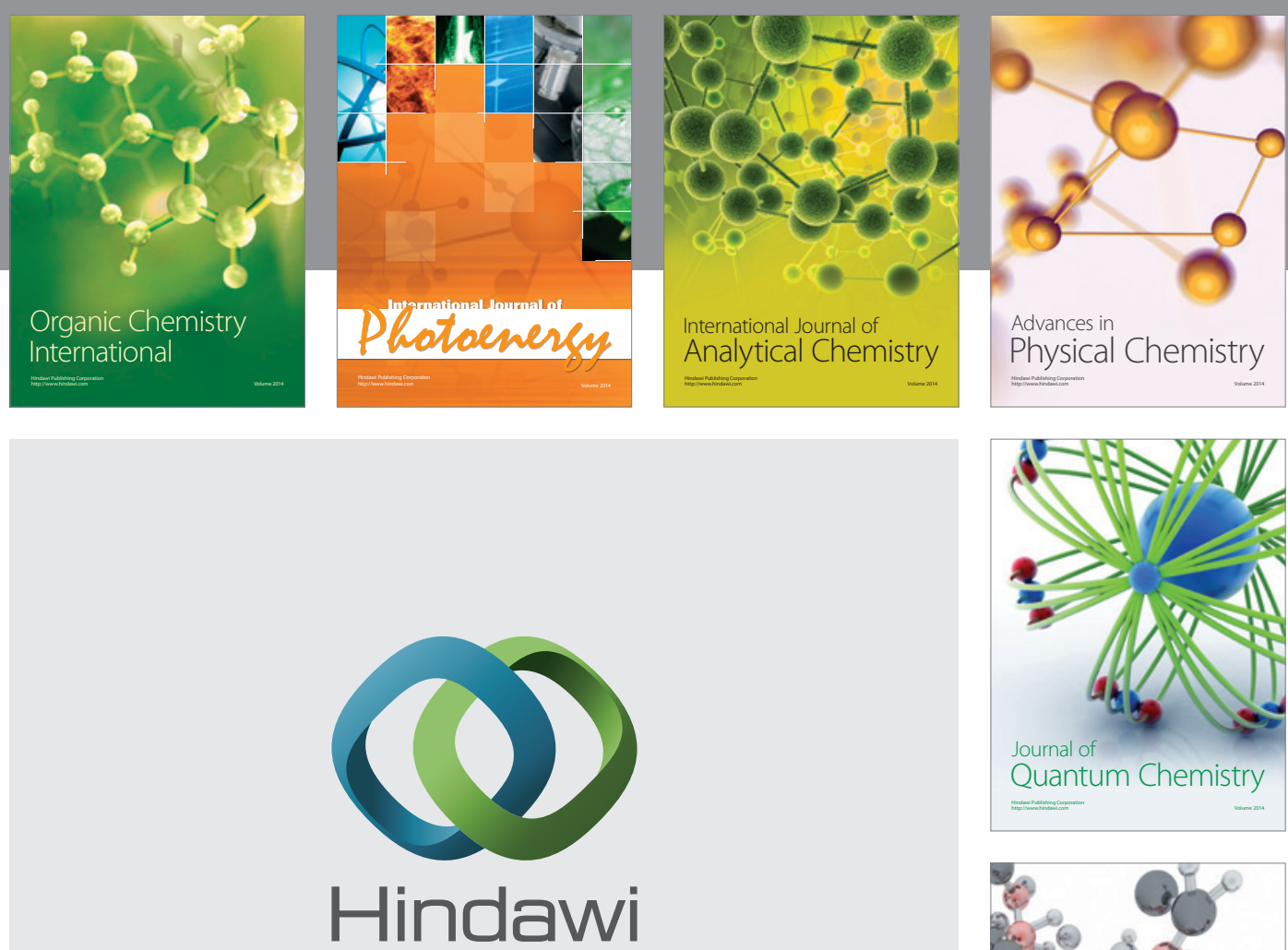

Submit your manuscripts at

https://www.hindawi.com

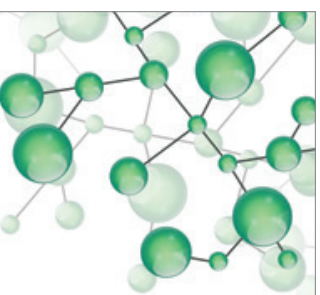

International Journal of

Inorganic Chemistry
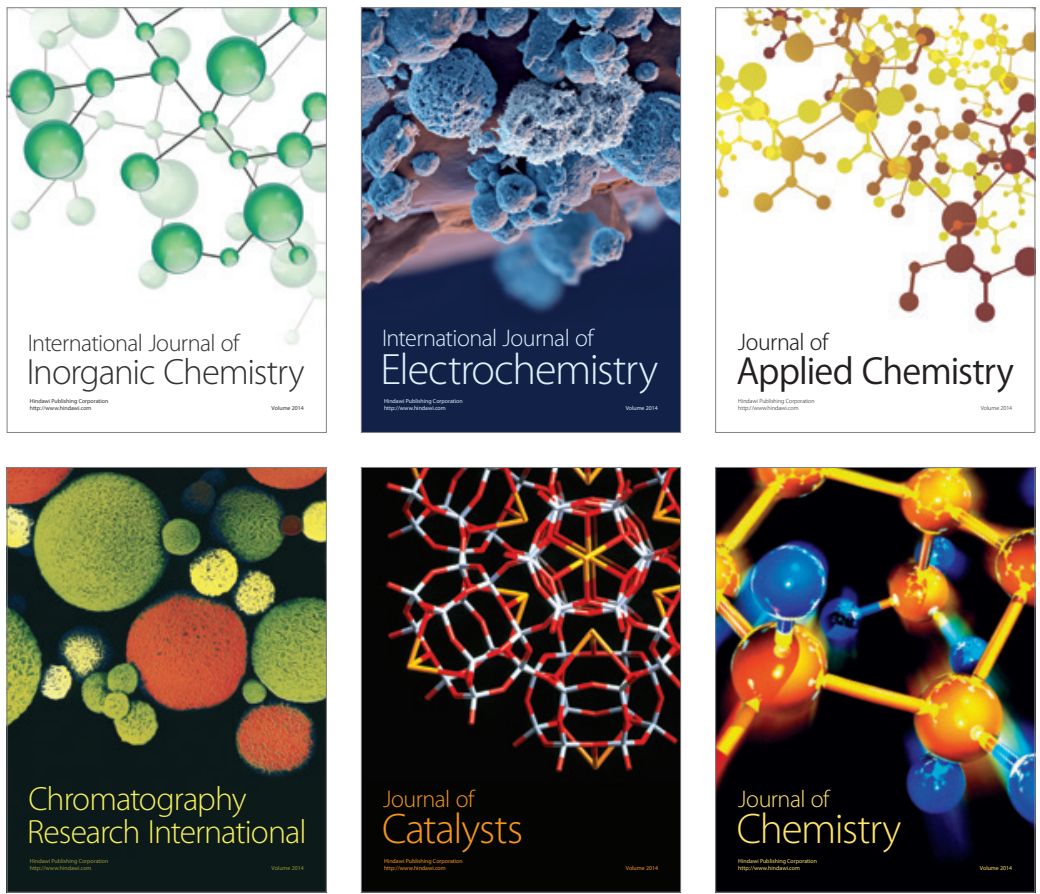

Journal of

Applied Chemistry
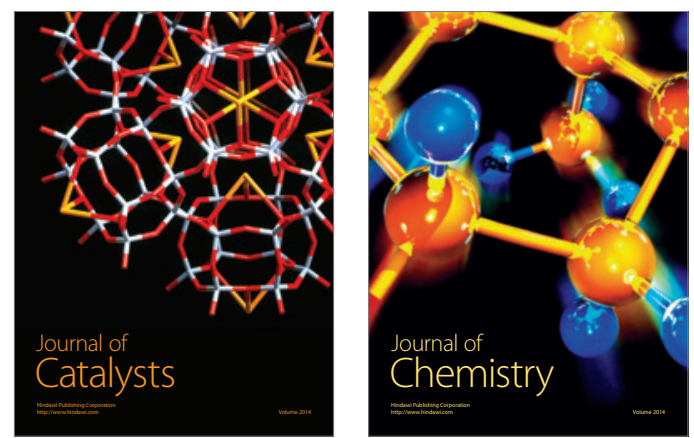
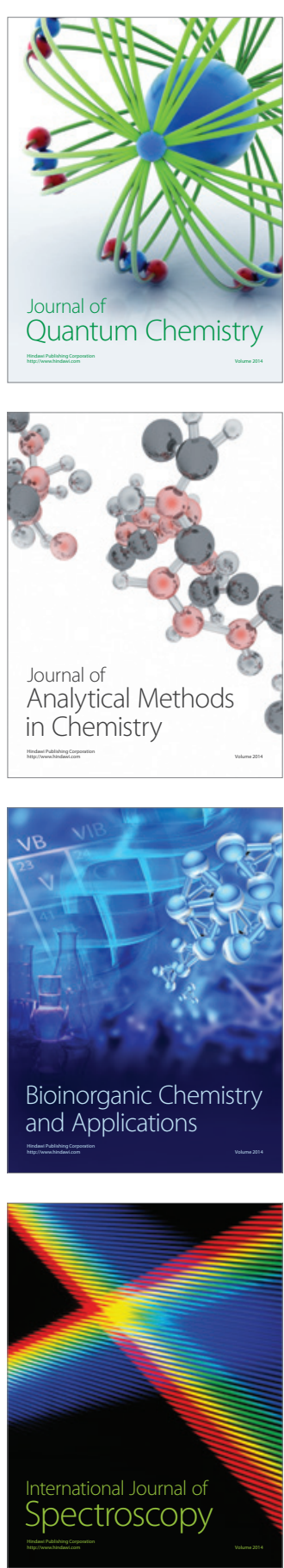